\title{
Survival and Prognostic Factors in Patients with Carcinoma of Cervical Stump
}

\author{
Hanan Ahmed Wahba', Hend Ahmed El-Hadaad', Waleed Nabeel Abozeed', \\ Waleed Elnahas ${ }^{2}$, Sameh Roshdy², Anas Gamal ${ }^{3}$ \\ ${ }^{1}$ Clinical Oncology and Nuclear Medicine, Mansoura University, Mansoura, Egypt \\ ${ }^{2}$ Surgical Oncology Unit, Mansoura Oncology Center, Mansoura University, Mansoura, Egypt \\ ${ }^{3}$ Obstetrics and Gynecology, Mansoura University, Mansoura, Egypt \\ Email: hend am@mans.edu.eg
}

Received 10 September 2015; accepted 25 October 2015; published 29 October 2015

Copyright (C) 2015 by authors and Scientific Research Publishing Inc.

This work is licensed under the Creative Commons Attribution International License (CC BY). http://creativecommons.org/licenses/by/4.0/

(c) (i) Open Access

\section{Abstract}

Purpose: To evaluate patients with carcinoma of cervical stump (CCS) and analyse different clinico-pathologic factors affect prognosis. Patients and Methods: This study was carried out through review of clinical records of patients. Recorded data included information on age, tumor stage, presenting symptoms, size of tumor, histopathology, grade, type, cause of subtotal hysterectomy (STH), treatment and follow-up results. Staging according to International Federation of Gynecology and Obstetrics (FIGO) staging system was done through: PHYSICAL examination, pelvic examination under anaesthesia, chest X-ray, magnetic resonance imaging (MRI) of the abdomen and pelvis, cystoscopy, rectosigmoidoscopy and intravenous pyelography. Prognostic factors as age, size of tumor, stage, lymph node (LN) involvement, pathological type, grade and type of CCS either true or coincidental were analysed through multivariate analysis. Results: $62 \%$ of patients are above 50 years with stage II in $\mathbf{4 8 . 7 \%}$. Squamous cell carcinoma was more common but $54 \%$ are of GIII. 89\% were true CCS. Positive lymph nodes were reported in $27 \%$. The predominant reason for STH was abnormal bleeding ( $73 \%$ ). In about $95 \%$ of cases, women seeked medical attention because of symptoms and the most common presenting symptom was bleeding (54\%). According to the stage and performance status of patients, treatment consisted of radiotherapy either external or interstitial, chemotherapy and chemoradiotherapy. Through multivariate analysis, the following was found to have adverse impact on survival: Coincidental type $(P=0.04)$, high grade $(P=$ 0.03), advanced stage $(P=0.01)$, larger tumor size $(P=0.02)$, lymph node involvement $(P=0.029)$ and older age $(P=0.035)$. While pathological type was not $(P=0.52)$. After median follow-up of 52 months; 5-year overall survival was $65 \%$. Conclusion: CCS has a low morbidity. Adverse survival outcomes can be anticipated in those patients with: high grade lesions, advanced stages, large tumor size, coincidental type, older age and positive lymph node involvement. 


\section{Keywords}

\section{Carcinoma of Cervical Stump, Chemo-Radiotherapy, Radiotherapy, Survival and Prognostic Factors}

\section{Introduction}

Sparing the cervix at time of hysterectomy which called subtotal hysterectomy (STH) was carried out in the past in order to reduce surgical complications as blood loss, vaginal vault prolapse, enterocele, ureteral injuries and vaginal cuff abscess [1]. However, three randomized controlled trials comparing perioperative or post-operative complications of total hysterectomy versus STH, concluded that there is no clinically significant difference between blood loss and surgical time in both approaches despite that STH may be associated with less blood loss and shorter surgical time [2]-[4]. Also, it was suggested that the retaining cervix reduce the adverse effect on psychosexual behavior of the patients. Roovers and colleagues [5] found that sexual activity did not change after surgery whether it was total or subtotal hysterectomy, this finding was also reported by El-Touky et al. [6]. But, the retaining cervix carries the risk of developing cervical stump symptoms as vaginal bleeding, pelvic pain and cervical malignancy. Carcinoma of cervical stump (CCS) has been divided into: 1) Coincidental cases, when detected within 2 years after hysterectomy suggesting presence of pre-existing disease that not recognized at time of surgery; 2) True cases, when detected later than 2 years and considered to arise de novo [1]. The aim of this study is to retrospectively review patients with CCS as regard age, clinical stage, histopathology, treatment and survival, also to determine clinico-pathologic factors which are prognostic for patients with CCS.

\section{Patients and Methods}

A retrospective review of the records of patients with CCS attended to Clinical Oncology and Nuclear Medicine Department, Mansoura University at the period from January 2000 to December 2013. Recorded data included information on age, tumor stage, presenting symptoms, size of tumor, histopathology, type, cause of STH, treatment and follow-up results, the institutional review board approved the study. Staging according to FIGO staging system [7] was carried out through: Physical examination, pelvic examination under anaesthesia, chest xray, magnetic resonance imaging (MRI) of the abdomen and pelvis, cystoscopy, rectosigmoidoscopy and intravenous pyelography. After treatment, all patients were followed-up every 3 months for the first year then every 4 - 6 months for 3 years then annually. At each visit, full physical examination was performed.MRI of abdomen and pelvis was done every six months.

Prognostic factors as age, size of tumor, stage, lymph node (LN) involvement, pathological type, grade and type of CCS either true or coincidental were analysed through multivariate analysis.

\section{Statistical Methods}

Statistical Package for Social Sciences (SPSS) version 15.0 (Chicago, IL, USA) was used for statistical analysis, Number and percentage for demographic data. The categorical variables were compared using chi-square and Fisher's Exact test. P-value of $<0.05$ indicate statistical significance. Kaplan-Meier test was used for survival function.

\section{Results}

This study included 37 patients Table 1 showed their demographic data; mean age was 54 years, 62\% of patients are above 50 years with stage II in $48.7 \%$. Squamous cell carcinoma was more common but $54 \%$ are of GIII. $89 \%$ were true CCS. Positive lymph nodes were reported in $27 \%$.

The predominant reason for STH was abnormal bleeding (73\%). In about 95\% of cases, women seeked medical attention because of symptoms and the most common presenting symptom was bleeding (54\%).

According to the stage and performance status of patients, treatment consisted of radiotherapy either external or interstitial, chemotherapy and chemoradiotherapy. Seventeen cases were treated by surgery followed by radiotherapy in the form of external pelvic irradiation at dose of 45 - $50 \mathrm{~Gy}$ followed by brachytherapy. Five cases received neoadjuvant radiotherapy followed by surgery, 11 patients were treated by chemoradiotherapy and 
Table 1. Demographic data.

\begin{tabular}{|c|c|c|}
\hline Character & No. & $\%$ \\
\hline Age: mean (range) & $54(43-68)$ years & \\
\hline$\leq 50$ years & 14 & 37.8 \\
\hline$>50$ years & 23 & 62.2 \\
\hline \multicolumn{3}{|l|}{ FIGO stage } \\
\hline I & 11 & 29.7 \\
\hline II & 18 & 48.7 \\
\hline III & 6 & 16.2 \\
\hline IV & 2 & 5.4 \\
\hline \multicolumn{3}{|l|}{ Pathological type } \\
\hline Squamous cell carcinoma (SCC) & 34 & 91.9 \\
\hline Adenocarcinoma (AC) & 3 & 8.1 \\
\hline \multicolumn{3}{|l|}{ Presenting symptoms } \\
\hline Bleeding & 20 & 54 \\
\hline Pain & 4 & 10.8 \\
\hline Vaginal discharge & 4 & 10.8 \\
\hline Combined symptoms & 7 & 18.9 \\
\hline Incident discovery & 2 & 5.4 \\
\hline \multicolumn{3}{|l|}{ Type of CCS } \\
\hline True & 33 & 89.2 \\
\hline Coincidental & 4 & 10.8 \\
\hline \multicolumn{3}{|l|}{ Causes of STH } \\
\hline Abnormal uterine bleeding & 27 & 73 \\
\hline Endometrial cancer & 8 & 21.6 \\
\hline Cervical cancer & 2 & 5.4 \\
\hline \multicolumn{3}{|l|}{ Size of tumor } \\
\hline$\leq 4 \mathrm{~cm}$ & 17 & 46 \\
\hline$>4 \mathrm{~cm}$ & 20 & 54 \\
\hline \multicolumn{3}{|l|}{ Grade } \\
\hline GI & 7 & 18.9 \\
\hline GII & 10 & 27.1 \\
\hline GIII & 20 & 54 \\
\hline \multicolumn{3}{|l|}{ Lymph node involvement } \\
\hline Positive & 10 & 27.1 \\
\hline Negative & 27 & 72.9 \\
\hline
\end{tabular}




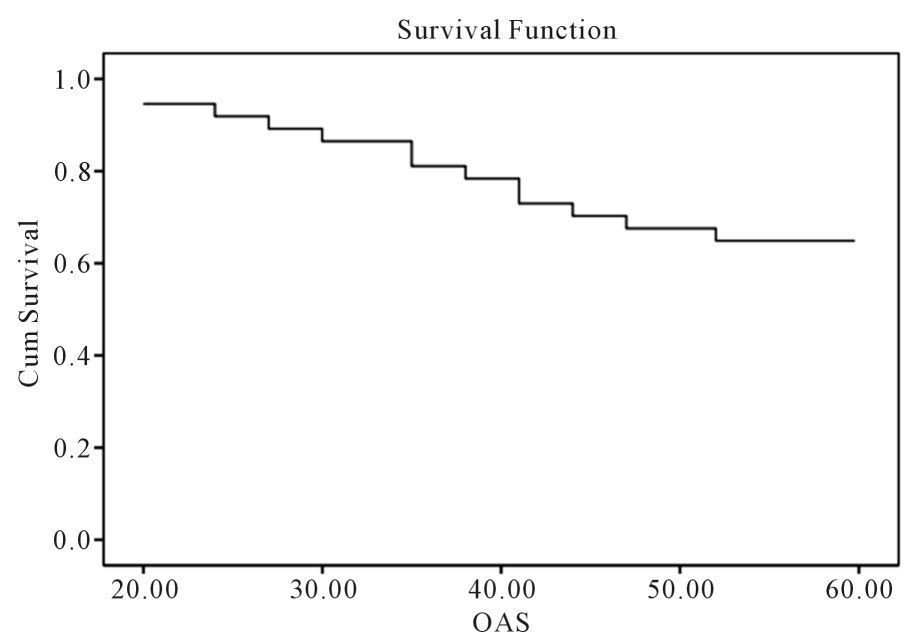

Figure 1. Over All Survival (OAS).

4 received chemotherapy alone.

Through multivariate analysis; the following was found to have adverse impact on survival: Coincidental type ( $P=0.04)$, high grade $(P=0.03)$, advanced stage $(P=0.01)$, larger tumor size $(P=0.02)$, lymph node involvement $(\mathrm{P}=0.029)$ and older age $(\mathrm{P}=0.035)$. While pathological type was not $(\mathrm{P}=0.52)$.

After median follow-up of 52 months; 5-year overall survival was 65\% (Figure 1).

\section{Discussion}

The main disadvantage of STH is the risk of developing CCS and the requirement for regular cervical screening following surgery [8]. So STH should be avoided whenever possible. CCS is found in $1 \%-3 \%$ of patients with STH and accounts for 3\% - 9\% of all cervical cancer [9] [10].

In our series; mean age was 54 years that was less than found by Hellström A.C., et al. [11].

Igboeli P., et al. [12] reported higher incidence of true CCS similar to that found in our patients.

The majority of our cases were diagnosed as stage II (48.7\%) and most of them with SCC (92\%), similar finding were reported by Hannoun-Levi J.M., et al. [13] and Petersen L.K. et al. [14].

Only $5 \%$ of cases were incidentally discovered. This can be explained by lack of screening after STH or some patients may not have received adequate information about the extent of the hysterectomy and therefore may have erroneously concluded that they no longer need cancer screening. Patients with coincidental CCS does worse than true one that was also found by Gibbons SK, Keys HM [15]. This can be explained by presence of disease which not recognized at time of STH.

It was found that AC cases had worse prognosis compares with the squamous cases [16]. But there was no significant impact of pathological type on survival in our patients; this result is not conclusive because of small number of AC patients (8\%).

Our results support the suggestion that high-grade, large tumor size $(4 \mathrm{~cm})$ and positive lymph node involvement adversely affect survival [17]-[19].

Calais G., et al. [20] mentioned that stage and nodal status had impact on prognosis; similar to our finding. Most authors have reported that experienced institutions can achieve survival results in patients with CCS comparable to those that are achieved in patients with carcinoma of intact cervix [13] [16] [21]. However, Igboeli P., et al. [12] has reported superior results with CCS cases when compared to those with an intact uterine cervix. In our patients, 5-year overall survival rate was comparable to that reported by Calais G., et al. [20] and Chen L., et al. [22].

\section{Conclusion}

CCS has a low morbidity. Adverse survival outcomes can be anticipated in those patients with: high grade lesions, advanced stages, large tumor size, coincidental type, older age and positive lymph node involvement. 


\section{References}

[1] Hasson, H.M. (1993) Cervical Removal at Hysterectomy for Benign Disease, Risk and Benefits. The Journal of Reproductive Medicine, 38, 781-790.

[2] Thakar, R., Ayers, S., Clarkson, P., Stanton, S. and Manyonda, I. (2002) Outcome after Total versus Subtotal Abdominal Hysterectomy. The New England Journal of Medicine, 347, 1318-1325. http://dx.doi.org/10.1056/NEJMoa013336

[3] Learman, L.A., Summitt Jr., R.L., Varner, R.E., McNeeley, S.G., Goodman-Gruen, D., Richter, H.E., et al. (2003) Total or Supracervical Hysterectomy (TOSH) Research Group. A Randomized Comparison of Total or Supracervical Hysterectomy: Surgical Complications and Clinical Outcomes. Obstetrics \& Gynecology, 102, 453-462. http://dx.doi.org/10.1016/S0029-7844(03)00664-1

[4] Gimbel, H., Zobbe, V., Andersen, B.M., Filtenborg, T., Gluud, C., et al. (2003) Randomised Controlled Trial of Total Compared with Subtotal Hysterectomy with One-Year Follow-Up Results. BJOG, 110, 1088-1098. http://dx.doi.org/10.1111/j.1471-0528.2003.02395.x

[5] Roovers, J.P., van der Bom, J.G., van der Vaart, C.H. and Heintz, A.P. (2003) Hysterectomy and Sexual Wellbeing: Prospective Observational Study of vaginal Hysterectomy, Subtotal Abdominal Hysterectomy, and Total Abdominal Hysterectomy. BMJ, 327, 774-778. http://dx.doi.org/10.1136/bmj.327.7418.774

[6] El-Toukhy, T.A., Hefni, M., Davies, A. and Mahadevan, S. (2004) The Effect of Different Types of Hysterectomy on Urinary and Sexual Function: A Prospective Study. Journal of Obstetrics and Gynaecology, 24, 420-425. http://dx.doi.org/10.1080/01443610410001685574

[7] Pecorelli, S., Zigliani, L. and Odicino, F. (2009) Revised FIGOs Staging for Carcinoma of the Cervix. International Journal of Gynecology \& Obstetrics, 105, 107-108. http://dx.doi.org/10.1016/j.ijgo.2009.02.009

[8] Pricop, M., Cocoş, M., Aursulesei, D., Strat, L., Gafencu, C. and Bendescu, M. (1999) Cancer of the Cervical Stump. Rev Med Chir Soc Med Nat lasi, 103, 161-162.

[9] Hellström, A.C., Sigurjonson, T. and Pettersson, F. (2001) Carcinoma of the Cervical Stump. The Radiumhemmet Series1959-1987. Treatment and Prognosis. A Case Control Study. Acta Obstetricia et Gynecologica Scandinavica, 80, 152-157.

[10] Pettersson, F. (1998) Secondary Prevention. Screening for Carcinoma of the Cervix. In: Kavanagh, J.J., et al., Eds., Cancer in Women, Blackwell Science, Oxford, 240-250.

[11] Hellström, A.C., Hellman, K., Pettersson, B.F. and Andersson, S. (2011) Carcinoma of the Cervical Stump: Fifty Years of Experience. Oncology Reports, 25, 1651-1654.

[12] Igboeli, P., Kapp, D.S., Lawrence, R. and Schwartz, P.E. (1983) Carcinoma of the Cervical Stump: Comparison of Radation Therapy Factors, Survival and Patterns of Failure with Carcinoma of the Intact Uterus. International Journal of Radiation Oncology*Biology*Physics, 9, 153-159. http://dx.doi.org/10.1016/0360-3016(83)90092-5

[13] Hannoun-Lévi, J.M., Peiffert, D., Hoffstetter, S., Luporsi, E., Bey, P. and Pernot, M. (1997) Carcinoma of the Cervical Stump: Retrospective Analysis of 77 Cases. Radiotherapy \& Oncology, 43, 147-153. http://dx.doi.org/10.1016/s0167-8140(97)01918-x

[14] Petersen, L.K., Mamsen, A. and Jakobsen, A. (1992) Carcinoma of the Cervical Stump. Gynecologic Oncology, 46, 199-202. http://dx.doi.org/10.1016/0090-8258(92)90255-h

[15] Gibbons, S.K. and Keys, H.M. (1996) Special Situations in the Management of Early Cervical Cancer. In: Rubin, S.C., Hoskins, W.J., Eds., Cervical Cancer and Preinvasive Neoplasia, Lippincott-Raven, Philadelphia, 259-260.

[16] Goodman, H.M., Niloff, J.M., Buttlar, C.A., Welch, W.R., Marck, A., Feuer, E.J., et al. (1989) Adenocarcinoma of the Cervical Stump. Gynecologic Oncology, 35, 188-192. http://dx.doi.org/10.1016/0090-8258(89)90041-3

[17] Miller, B.E., Copeland, L.J., Hamberger, A.D., Gershenson, D.M., Saul, P.B., Herson, J., et al. (1984) Carcinoma of the Cervical Stump. Gynecologic Oncology, 18, 100-108. http://dx.doi.org/10.1016/0090-8258(84)90012-x

[18] Barillot, I., Horiot, J.C., Cuisenier, J., Pigneux, J., Schraub, S., Rozan, R., et al. (1993) Carcinoma of the Cervical Stump: A Review of 213 Cases. European Journal of Cancer, 39, 1231-1236. http://dx.doi.org/10.1016/0959-8049(93)90063-L

[19] Kovalic, J.J., Grigsby, P.W., Perez, C.A. and Lockett, M.A. (1991) Cervical Stump Carcinoma. International Journal of Radiation Oncology*Biology*Physics, 20, 933-938. http://dx.doi.org/10.1016/0360-3016(91)90188-a

[20] Calais, G., Leloup, R., Chauvet, B., Body, G., Lansac, J., Bougnoux, P., et al. (1989) Carcinoma of the Cervical Stump. Retrospective Analysis of 43 Cases. Bull Cancer, 76, 1103-1110.

[21] Porpora, M.G., Nobili, F., Pietrangeli, D. and Falqui, L. (1991) Cervical Stump Carcinoma Therapy. European Journal of Obstetrics and Gynecology, 12, 45-50.

[22] Chen, L., Xia, T., Yang, Z. and Zhu, J. (2009) Comprehensive Treatment and Prognostic Factors in Patients with Carcinoma of the Cervical Stump. Clinical Oncology and Cancer Research, 6, 426-429. 